\title{
Evaluation of Cob Characteristics and Yield Response of Sweet Corn with different Irrigation Treatments
}

\author{
B. Naveena ${ }^{1 *}$ and G. Ravi Babu ${ }^{2}$ \\ ${ }^{1}$ Department of Agricultural Engineering, ${ }^{2}$ Department of Soil and Water Conservation \\ Engineering, College of Agricultural Engineering, Bapatla, ANGRAU, A.P., India \\ *Corresponding author
}

Keywords

Drip irrigation, Micro irrigation, Automation systems, Single row

Article Info

Accepted:

10 January 2021

Available Online:

10 February 2021
Drip irrigation, one of the micro irrigation methods, is an efficient method of providing irrigation water directly into soil at the root zone of plants at very low rates (2-20 litres/hour) from a system of small diameter plastic pipes fitted with emitters or drippers. A few low cost automation systems were developed and evaluated their performance with drip irrigation on sweet corn on the sandy soils of College of Agricultural Engineering, Bapatla. It was observed that single row drip irrigation showed better results compared to flood irrigation and paired row drip irrigation. The results indicated that the number of kernel rows per cob, number of kernels per cob, length and diameter of the cob and individual fresh cob weight were observed to be more in single row as compared to flood irrigation and paired row drip irrigation systems. The yield response was also observed to be best in soil moisture sensor based irrigation with single row spacing.

\section{Introduction}

Major consumption of water is for agriculture, industrial production and domestic purposes, apart from being used for fishery, hydro power generation, transportation and maintaining bio-diversity and ecological balance. The proportion of water is used for agriculture and an industry varies from country to country depending on the lifestyle. While the per capita water use in India will increase from the current level of 99 litres per day to 167 litres per day in 2050 then India will be the highest water demanding country, needing 2413 billion litres per day (Boaz, 2015). Land and water are the basic needs for agriculture and economic development of the country. A study by the International Water Management Institute (IWMI) has shown that around 50 per cent of the increase in demand for water by 
the year 2025 can be met by increasing the effectiveness of irrigation (Seckler et al., 1998). Plants and animals cannot live without water and to ensure food security, feed live stock, maintain organic life, and take up industrial production and to conserve the biodiversity and environment water is needed.

Hence, there is no life without water. Although India is not a water poor country, due to growing human population severe neglect and over exploitation of this resource, water is becoming a scarce commodity.

Agriculture marks the beginning of 'civilized' or 'sedentary' society. India had a stagnant performance of Agriculture in during the colonial period which turned into a sustained growth then with a stronger performance in India especially in terms of per capita food production the Indian Agricultural Industry grew. Irrigation has been considered essential for the fast growth of agriculture which consumes 80 percent of the country's exploitable water resources. Micro irrigation technology is now widely accepted by most of the farmers in the world. In this system water is applied close to the root of the plants which provides right amount of water required for the growth of the plant and avoids excessive wastage of water, unlike surface and flood irrigation, which wets the whole soil profile and sometime causes soil erosion and soil nutrient loss.

Drip irrigation is an efficient method of providing irrigation water directly into soil at the root zone of plants and thus, minimizes conventional losses such as deep percolation, runoff and soil erosion. With drip irrigation water applications are more frequent than with other methods and this provides a very favourable high moisture level in the soil in which plants can flourish. There are lots of benefits of automation in drip irrigation- the real time useful controlling system for monitoring and controlling all activities of drip irrigation more efficiently. Drip method helps in achieving saving in irrigation water, increased water-use efficiency, higher quality products, decreased tillage requirement, increased crop yields and higher fertilizer-use efficiency (Sivanappan, 2002; Namara et al., 2005).

Sweet corn is a high moisture commodity and sold on the basis of high quality alone. It is very succulents, has a rather shallow root system and does not yield well if adequate soil water is not readily available (Vittum et al., 1963). Irrigating sweet corn with micro-drip (emitter discharge of less than $0.51 / \mathrm{h}$ ) irrigation may improve yield, reduce drainage flux (excess water removal) and affect the water content distribution within the root zone especially within $0.6-0.9 \mathrm{~m}$ soil layer when compared with the conventional drip irrigation (Assouline, 2002).

The amount of water applied per day, leaf-air temperature and soil moisture content were monitored (Noble et al., 2000). The aim of the present work was to determine the crop growth characteristics of sweet corn under single row and paired row drip irrigation systems.

\section{Materials and Methods}

\section{Preparation of the field}

The experiment was conducted in the field irrigation laboratory, Department of Soil and Water Engineering, College of Agricultural Engineering, Bapatla.

The experimental site lies in humid sub tropical area. The summers are dry and hot, where as winter is cool. The experimental site consists of sandy soil with well drained conditions. The field was prepared by cultivator and rotavator for loosening the soil 
and for removal of weeds prior to sowing the sweet corn seeds. After one week of applying about $100 \mathrm{~kg}$ of farm yard manure throughout the field having an area of $1330 \mathrm{~m}^{2}$ for sweet corn plot, once again the plot was tilled with rotavator to mix the dried farm yard manure thoroughly in the soil.

\section{Water source}

For supplying the water, an existing open well near the experimental site was utilized. To know the suitability of water for irrigation, the quality of water was assessed and found that $\mathrm{pH}$ and $\mathrm{EC}$ of water is 7.2 and $4 \mathrm{dS} / \mathrm{m}$ respectively.

\section{Irrigation accessories}

\section{Main pipe}

To convey water from source to the experimental site through sub mains a PVC pipe of $63 \mathrm{~mm}$ diameter (Class 2, $4 \mathrm{kgf} / \mathrm{cm}^{2}$ ) was used.

\section{Sub main}

To convey water from main lines to laterals a PVC pipe of $50 \mathrm{~mm}$ diameter (Class 3, 6 $\mathrm{kgf} / \mathrm{cm}^{2}$ ) was used as sub main pipe.

\section{Lateral pipe}

To supply water directly to the plant root zone from sub main pipes, a LLDPE pipe was used. The laterals are of inline type with the following specifications.

Outer diameter - $16 \mathrm{~mm}$

Wall thickness - $0.80 \mathrm{~mm}$

Flow rate $-2.00 \mathrm{lph}$ at $1 \mathrm{~kg} / \mathrm{cm}^{2}$ pressure

Spacing of drippers $-40 \mathrm{~cm}$

\section{Pump}

For pumping water a centrifugal mono block pump of $1 \mathrm{hp}$ capacity is used.

\section{Screen filter}

The screen filter normally consists of stainless steel screen of 120 mesh $(0.13 \mathrm{~mm})$ size, which is enclosed in a mild steel body. Filtration is achieved by the movement of water through the stainless steel mesh. Specifications are as follows.

Maximum flow capacity $-27 \mathrm{~m}^{3} / \mathrm{hr}$

Nominal size - $50 \mathrm{~mm}$

Nominal pressure $-2 \mathrm{~kg} / \mathrm{cm}^{2}$

Size of aperture - 120 mesh

Clean pressure drop $-0.5 \mathrm{~kg} / \mathrm{cm}^{2}$ maximum.

\section{Sand filter}

Media filters consist of fine gravel or coarse quartz sand, of selected sizes (usually $1.5-4$ $\mathrm{mm}$ in diameter) free of calcium carbonate placed in a cylindrical tank. These filters are effective in removing light suspended materials, such as algae and other organic materials, fine sand and silt particles. This type of filtration is essential for primary filtration of irrigation water from open water reservoirs, canals or reservoirs in which algae may develop.

\section{Working principle involved in the soil moisture sensor}

The basic working principle involved in the development of soil moisture sensor circuits electrical conductivity. As the moisture content of the soil increases, the electrical conductivity of the soil increases. The 
electrical conductivity of the probes can be related to the soil moisture of the soil. Usually the electrical conductivity is read manually from a multimeter. In this experiment, sensors which detect the soil moisture in the soil (agricultural field) and supply water to the field which requires irrigation water. The developed sensor as shown in Plate 3.3 is 8051 microcontroller based design which controls the water supply and the field to be irrigated using solenoid valves.

The sensor present in each field stops the pump automatically through microcontroller when the field reached to its field capacity.

Once the field reaches to $70 \%$ of field capacity, sensors sense the requirement of water in the field and send a signal to the microcontroller. Microcontrollers then supply water to that particular field for which water requires, till the sensors are deactivated again.

\section{Results and Discussion}

\section{Cob characteristics}

To study the sweet corn cob characteristics, 1 $\mathrm{m}^{2}$ area was selected in each treatment. The observed cob characteristics are no. of kernel rows per cob, no. of kernels per cob, cob length and cob diameter and the fresh cob weight. The no. of cobs in $1 \mathrm{~m}^{2}$ area is collected and average of those cobs is to be represented below.

\section{Number of kernel rows per cob}

It was observed that the cob characteristics for sweet corn was vary in different treatments of irrigation. Firstly no. of kernel rows per cob in single row drip method shows 16.8 followed by flood irrigation and then paired row drip method. The graphical representation between no. of kernel rows per cob and different irrigation treatments is shown in Fig. 1.

\section{Number of kernels per cob}

The single row drip method shows more no. of kernels per cob having 755.2 followed by flood irrigation having 656.8 and then paired row drip method having 558.8 as like as number of kernel rows/cob.

\section{Cob length}

The cob length for sweet corn was varying in different treatment of irrigation. The cob length is more in single row drip method compared to flood irrigation and paired row drip method. The cob length was measured from below the shank position to the bottom of the cob and it is done by the vernier callipers. The relation between cob length and irrigation treatment was shown in Fig. 3.

\section{Cob diameter}

The cob diameter for sweet corn was varying in different treatment of irrigation. The cob diameter is more in single row drip method compared to flood irrigation and paired row drip method. The cob diameter was measured at the centre of the cob and it is done by the Vernier callipers.

\section{Individual fresh cob weight}

The single row drip method shows more weight having $405.2 \mathrm{gm}$ followed by flood irrigation having $367.6 \mathrm{gm}$ and then paired row drip method having $226.6 \mathrm{gm}$.

\section{Yield response of sweet corn with different irrigation treatments}

The total yield of sweet corn for different experimental plots was calculated and presented in Table 3.1. The yield from the plot-1 (flood irrigation), plot-2 (single row drip), plot-3 (paired row drip) was observed as $7.43 \mathrm{t} / \mathrm{ha}, 7.93 \mathrm{t} / \mathrm{ha}$ and $6.48 \mathrm{t} / \mathrm{ha}$ respectively. 
Table.1 Yield of the sweet corn under the different irrigation systems

\begin{tabular}{|c|c|c|c|c|c|}
\hline S.No & $\begin{array}{c}\text { Type of } \\
\text { irrigation } \\
\text { system }\end{array}$ & Plot size & $\begin{array}{c}\text { Yield } \\
\text { per plot } \\
\text { (kg) }\end{array}$ & $\begin{array}{c}\text { Yield } \\
\text { (kg/ha) }\end{array}$ & $\begin{array}{c}\text { Yield } \\
\text { (t/ha.) }\end{array}$ \\
\hline $\mathbf{1 .}$ & Flood & $12 \mathrm{~m} \times 35 \mathrm{~m}$ & 312 & 7429 & 7.43 \\
\hline $\mathbf{2 .}$ & Single row drip & $12 \mathrm{~m} \times 35 \mathrm{~m}$ & 333 & 7929 & 7.93 \\
\hline $\mathbf{3 .}$ & Paired row drip & $12 \mathrm{~m} \times 35 \mathrm{~m}$ & 272 & 6476 & 6.48 \\
\hline
\end{tabular}

Fig.1

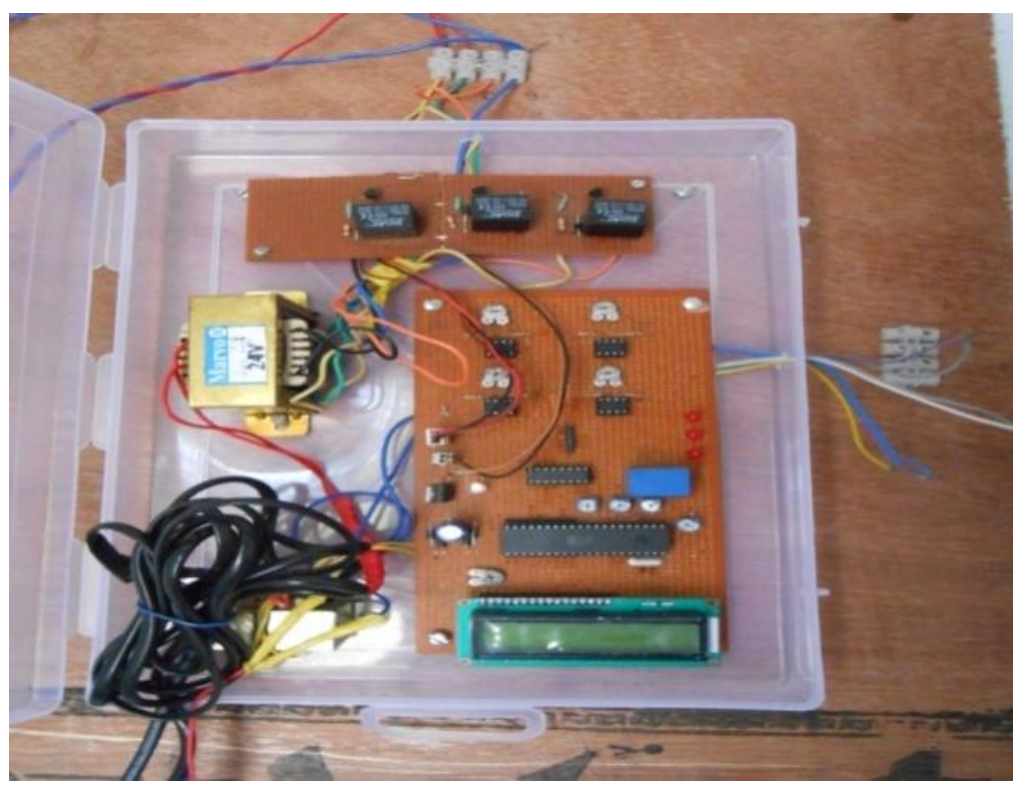

Fig.2 Relationship between no. of kernel rows per cob and Irrigation treatment

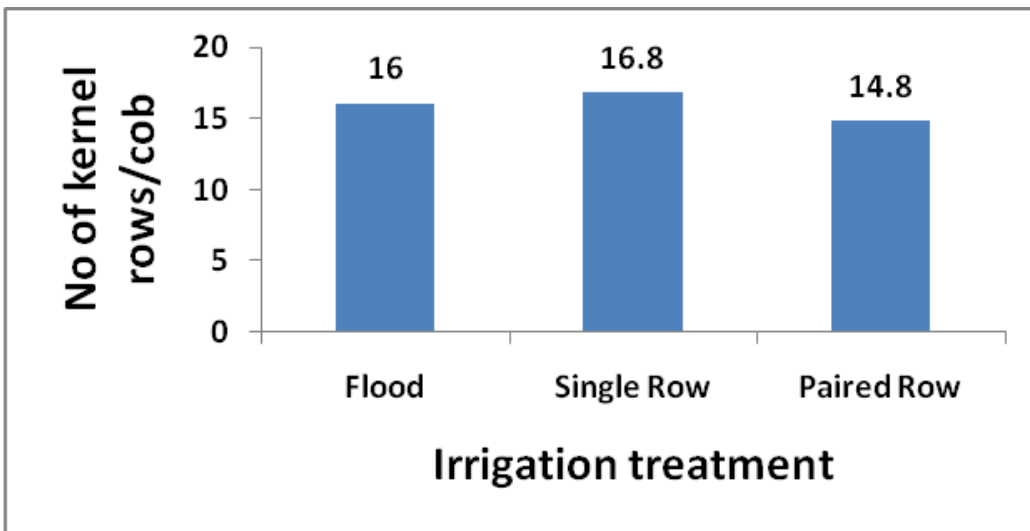


Fig.3 Relationship between no. of kernels per cobs vs. irrigation treatment

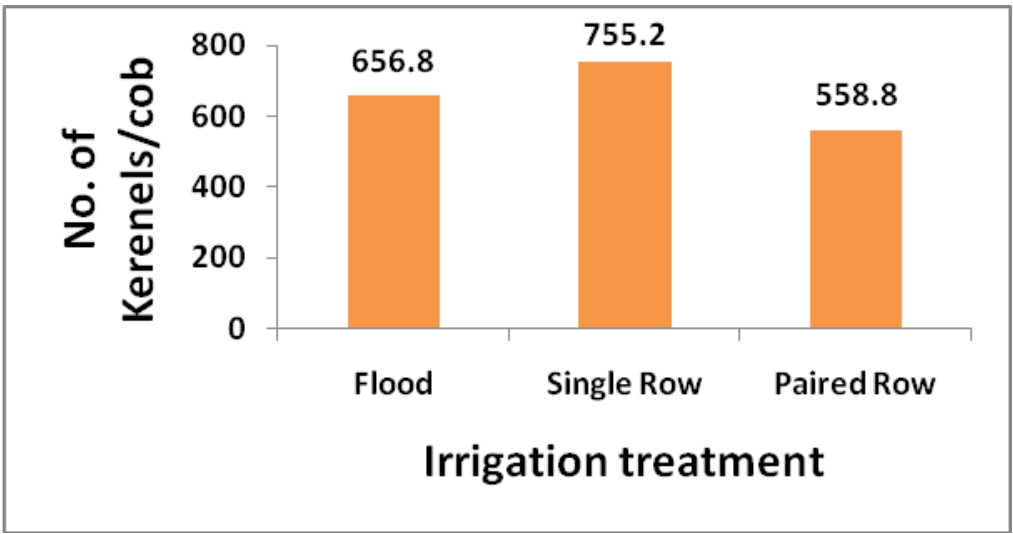

Fig.4 Relationship between cob length and irrigation treatment

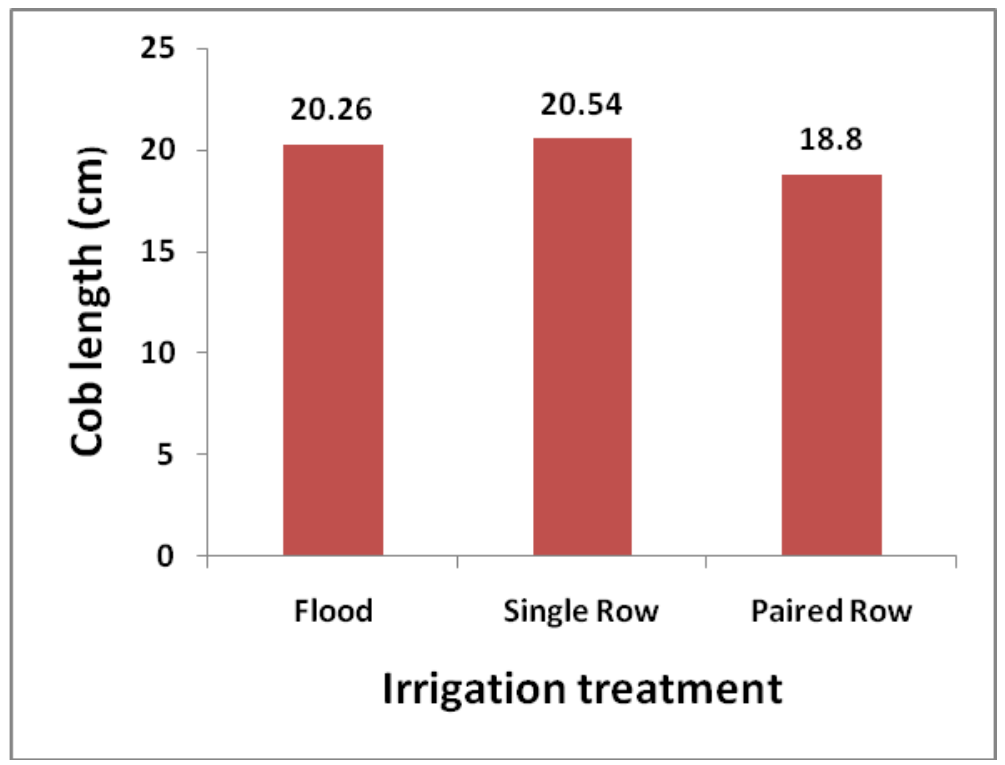

Fig.5 Relationship between cob diameter and Irrigation treatment

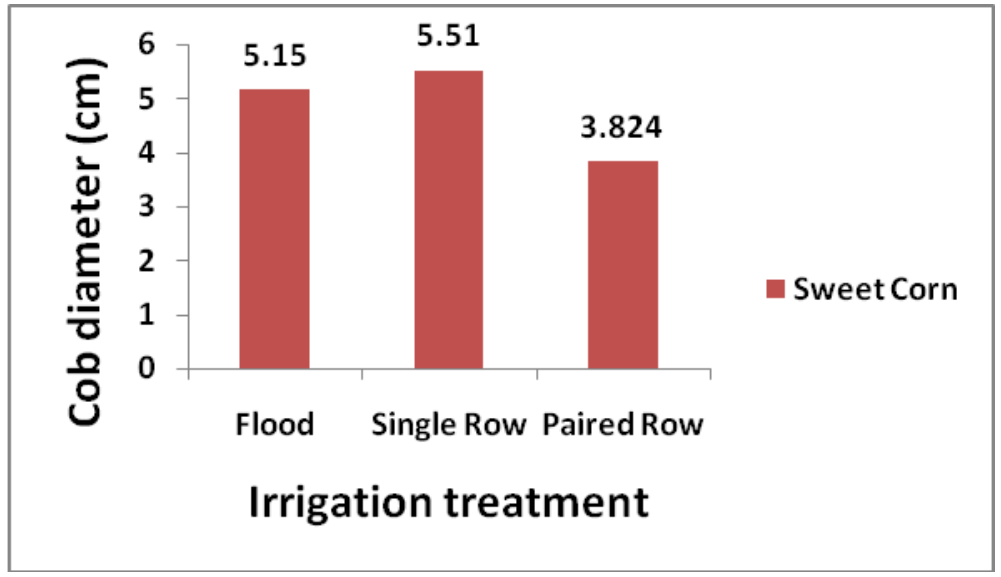


Fig.6 Relationship between fresh ear weight and Irrigation treatment

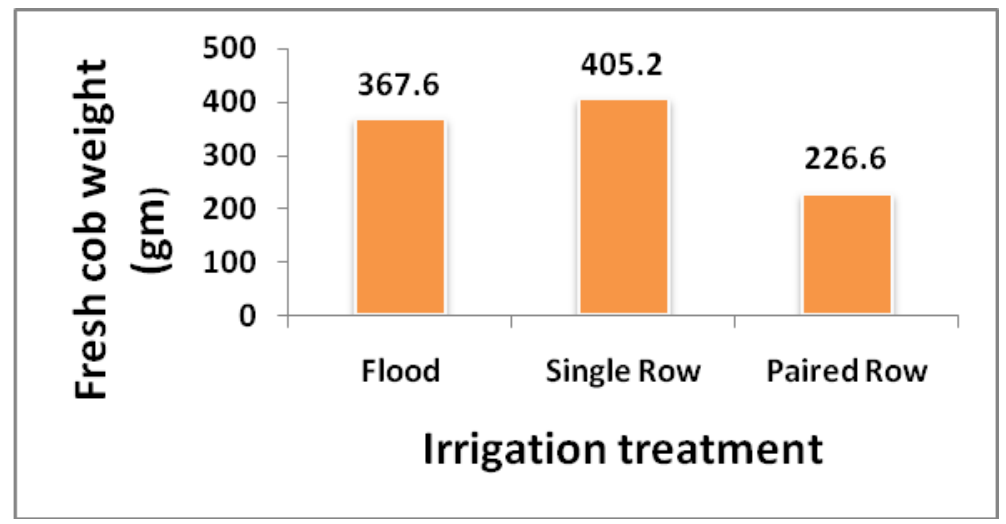

Fig.7 Relationship between total yield and irrigation treatment

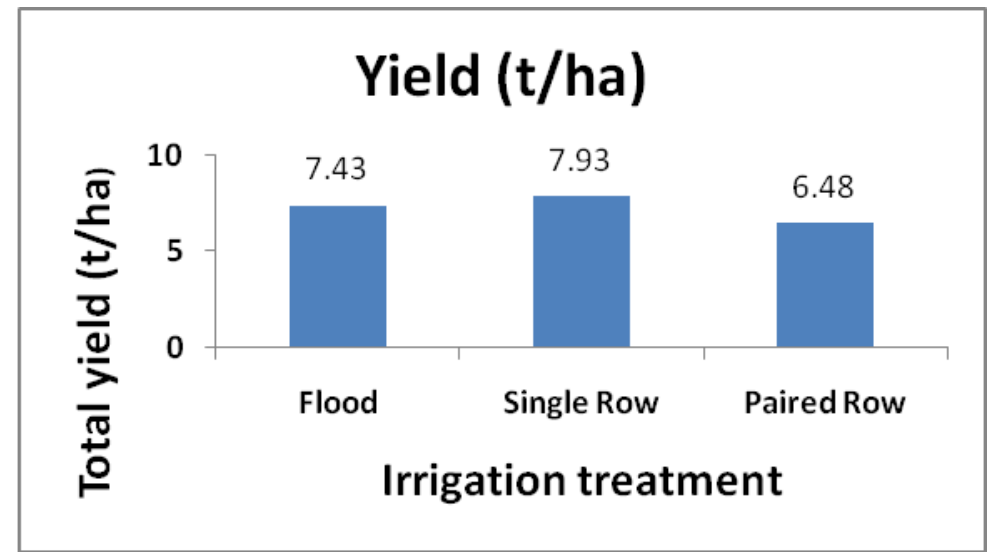

The yield of the plot- 2 was observed to be higher when compared to the yield obtained from the other experimental plots. The higher yield can be obtained due to the efficient application of water at correct time near the root zone by low cost microcontroller based soil moisture sensor which is present in the field and supplies water automatically whenever there is need of water to the plant which helps for the favourable conditions for growth of the plant.

Yield values of sweet corn were compared against different irrigation systems as shown in Fig. 6. The yield of sweet corn for single row drip is $6.72 \%$ more as compare to flood irrigation. The sensor with washed sand as porous medium was found to be the most efficient one and a low cost, commercially available button type thermistor was used as the leaf and air temperature sensors for the study area.

The amount of water applied per day, leaf-air temperature and soil moisture content were monitored (Noble et al., 2000).

The number of kernel rows per cob, number of kernels per cob, length of the cob, diameter of the cob and individual fresh cob weight were observed to be more in single row as compared to flood irrigation and paired row drip irrigation systems. Overall, the yield response was observed to be best in soil moisture sensor based irrigation with single row spacing. 


\section{References}

Assouline, S. (2002). The Effect of Micro drip and Conventional Drip Irrigation on Water Distribution and Uptake. Soil Science Society of America Journal. 66(5): 1630-1636.

Boaz, A. 2015. Water scarcity a threat for Agriculture. Journal of Agriculture and Rural Development. 42(5): 42-44.

Namara, Regassa E., Upadhyay, Bhawana and Nagar, R.K. (2005) Adoption and Impacts of Microirrigation Technologies : Empirical Results from Selected Localities of Maharashtra and Gujarat States of India, Research Report 93, International Water Management Institute (IWMI), Colombo, Sri Lanka.

Noble, A., Hema, P.S., Saritha, E.K. and Subramannian, S. 2000. Irrigation automation based on soil electrical conductivity and leaf temperature. Agricultural Water Management. 45: 145-157.

Seckler, David, Amarasinghe, Upali, Molden, David, de Silva, Radhika and Barker, Randolph (1998) World Water Demand and Supply, 1990 to 2025: Scenarios and Issues, Research Report 19, International Water Management Institute (IWMI), Colombo, Sri Lanka.

Sivanappan, R.K. (2002) Strengths and weakness of growth of drip irrigation in India, In: Proc. Of Micro Irrigation for Sustainable Agriculture. GOI Short-term training 19-21 June, WTC, Tamil Nadu Agricultural University, Coimbatore.

Vittum, M.T. and W. J. Flocker. (1963). Vegetable Crop. America Society of Agronomy Monograph Series 11, 682683, America Society of Agronomy, Madison Wisconsin, USA.

\section{How to cite this article:}

Naveena, B. and Ravi Babu, G. 2021. Evaluation of Cob Characteristics and Yield Response of Sweet Corn with different Irrigation Treatments. Int.J.Curr.Microbiol.App.Sci. 10(02): 11921199. doi: https://doi.org/10.20546/ijcmas.2021.1002.140 